\title{
A AUTORREPRESENTAÇÃO DA DIVERSIDADE SOCIAL - DIFERENÇA - E A LUTA PELA REINSERÇÃO SOCIAL: UMA ANÁLISE DO DOCUMENTÁRIO CARTS OF DARKNESS
}

\author{
THE SELF-REPRESENTATION OF SOCIAL DIVERSITY \\ DIFFERENCE - AND THE STRUGGLE SOCIAL REINTEGRATION: \\ AN ANALYSIS OF DOCUMENTARY CARTS OF DARKNESS
}

LARA LIMA DE OLIVEIRA PAIVA

Mestranda em Comunicação, Cultura e Cidadania pela Universidade Federal de Goiás - FACOMB. Linha de Pesquisa: Mídia e Cultura. E-mail: larapaiva@hotmail.com. Maria LUIZA MARTINS de MENDONÇA Co-autora: Prof.a Dra. do Curso de Comunicação Social da FACOMB-UFG. E-mail: mluisamendonca@gmail.com.

1 Esse documentário recebeu o prêmio Film Festival Hot Docs 2009, em Toronto, na categoria: Melhor Documentário Com Mais de 30 minutos.

\section{RESUMO}

A partir da busca desenfreada pela(s) identidades(s) na era pós-moderna e na luta pela inserção social dos indivíduos, esse estudo se propõe a fazer uma análise do discurso cinematográfico do documentário canadense Carts of Darkness, como ferramenta estratégica para dar voz, na sociedade, aos grupos minoritários na busca de sua emancipação.

Palavras-chave: Representação. Cinema documental. Identidades. Diversidade Social.

\section{ABSTRACT}

From an intense search for the multiples identities in the "post-modern" era as well as the symbolic fight for the individual's social inclusion, this study proposes a cinema discourse analysis of the Canadian documentary "Carts of Darkness", as an appropriate tool to help the minor groups emancipate.

Keywords: Representation. Documentary Film. Identities. Social Diversity.

\section{Uma questão de identidade}

Falar das representações dos grupos minoritários das sociedades contemporâneas é falar, entre outros, da construção da identidade do indivíduo pós-moderno assim como contextualizá-la sócio e culturalmente na realidade na qual está inserida. O objeto de estudo desse trabalho é o documentário canadense Carts of Darkness $^{l}$ (2008), que é uma autorrepresentação da vida do cineasta (e snowboarder) Murray Siple em sua busca identitária. Este estudo se propõe a analisar esse produto cinematográfico 
como uma ferramenta estratégica emancipatória.

A era pós-moderna ou modernidade líquida (BAUMAN, 2001) é caracterizada pela busca desenfreada do indivíduo na construção de sua(s) identidade(s). Esta, por sua vez, não é mais fixa / determinada pelo lugar do indivíduo na sociedade (como era nos tempos coloniais e iluministas) e sim fluida, mutante e instável. A identidade agora é determinada pelas ações e pelo comportamento desse indivíduo, na qual a palavra de ordem é "estar em movimento" (BAUMAN, 2005, p.38).

A busca da identidade nos tempos de hoje é antes de tudo contraditória e, portanto, a busca do impossível. Segundo BAUMAN (1998, p.74,75), o indivíduo sente-se constantemente incompleto e, portanto, em constante estado de risco e, a sua busca pela identidade nada mais é do que a busca pela segurança que o mundo atual não the oferece. Esta procura gera-lhe ansiedade diante da contradição ao buscar a segurança, na qual a ordem é a mudança, e o fato de encontrar uma identidade fixa significa ser um outsider. "Em nossa época líquido-moderna, em que o indivíduo livremente flutuante, desimpedido, é o herói popular, 'estar fixo' - ser 'identificado' de modo inflexível e sem alternativa - é algo cada vez mais malvisto." (BAUMAN, 2005, p.35).

A instabilidade dessa nova era faz do indivíduo um ser que vive o presente buscando o futuro, portanto o prazer está em buscar identidade e não em construí-la. Assim, a construção $\mathrm{da}(\mathrm{s})$ identidade(s) na socieda- de pós-moderna pode ser vista como um grande mosaico, uma vez que os indivíduos podem, ao mesmo tempo, fazer parte de diferentes grupos sociais sem que uma identidade interfira sobre a outra. Porém, como em uma era caracterizada pela insegurança, o indivíduo pode fazer suas escolhas, mas não pode ter controle sobre seus resultados.

...é preciso compor a sua identidade pessoal (ou as suas identidades pessoais?) da forma como se compõe uma figura com as peças de um quebra-cabeça, mas só se pode comparar a biografia com um quebra-cabeça incompleto, ao qual faltem muitas peças (e jamais se saberá quantas) [...], há um monte de pecinhas na mesa que você espera poder juntar formando um todo significativo - mas a imagem que deverá aparecer no fim do seu trabalho não é dada antecipadamente, de modo que você não pode ter a certeza de ter todas as peças necessárias para montá-la, de haver selecionado as peças certas entre as que estão sobre a mesa, de tê-las colocado no lugar adequado ou de que elas realmente se encaixam para formar a figura final (BAUMAN, 2005, p.54-55).

Nesse cenário, é interessante ainda destacar o conceito de BAUMAN (1998, 2005) sobre comunidades guarda-roupa dessa nova era. De acordo com ele, essas são comunidades nas quais as pessoas integram pelo tempo que durar o "espetáculo".

A construção da identidade na pós-modernidade é também 
composta pelo reconhecimento do olhar do outro, tendo ele poder para legitimar uma posição assumida voluntariamente pelo indivíduo, ou ainda, para colocálo em uma posição estereotipada como forma de afirmação de uma posição hegemônica. A alteridade é uma peça chave para que esta identidade seja autenticada e reconhecida pela sociedade como um todo.

Na modernidade, a identidade torna-se mais móvel, múltipla, pessoal, reflexiva e sujeita a mudanças e inovações. Apesar disso, também é social e está relacionada com o outro. Certos teóricos da identidade, desde Hegel até G.H. Mead, frequentemente caracterizavam a identidade pessoal em termos de reconhecimento mútuo, como se a identidade de uma pessoa dependesse do reconhecimento de outras, em combinação com a validação dada por essa pessoa a esse reconhecimento (KELLNER, 2001, p.295).

Esse "olhar do outro" sob os grupos minoritários ${ }^{2}$ vem sendo construído sócio-historicamente, a partir de uma visão eurocêntrica, (SHOHAT \& STAM, 2006), de mundo na busca pela manutenção do poder hegemônico que utiliza-se da mídia para disseminação dos valores dessa

2 Sabe-se que existe distinção e, portanto, uma confusão quanto aos termos: grupos minoritários e grupos subalternos. Porém, neste caso, será utilizado o termo grupos minoritários pelo fato do grupo de portadores de necessidades especiais ser considerado tanto minoritário quanto subalterno (marginalizado) na sociedade. cultura hegemônica. Segundo FREIRE FILHO (2005, p.20) a cultura da mídia desempenha um significativo papel “(...) na formulação, no reconhecimento e na legitimação de modelos daquilo que significa ser mulher ou homem, moral ou imoral, feio ou bonito..."
O outro é uma constituinte de nossa identidade; por conseguinte, nos últimos tempos é bem comum a personagem determinada pelo 'outro'; ela depende dos outros para o reconhecimento e, portanto, para o estabelecimento de sua identidade pessoal (KELLNER, 2001, p.296).

Porém, essa realidade está em processo de mudança, ou ainda, de reformulação da visão unilateral - hegemônica - do mundo. A partir dessa liberdade da construção da identidade na era pós-moderna, os grupos minoritários (índios, negros, homossexuais, mulheres etc.) se depararam com a oportunidade de terem voz e se representarem na sociedade utilizando-se para isso da mídia, fato antes negado a eles pelos grupos de poder grupos marginalizados, portanto vozes marginalizadas. (FREIRE FILHO, 2005, p.19). Além disso, não tinham controle sobre sua representação social estereotipada e/ou distorcida. (SHOHAT \& STAM, 2006, p.270)

Assim, como o outro é determinante na constituição da identidade do indivíduo, a autorrepresentação no cinema e na mídia em geral, vem se disseminando como uma das maneiras encontradas pelos grupos minoritários de se afirmarem, oferecendo à sociedade um novo olhar sobre os grupos marginalizados, na busca de sua emancipação, ou ainda reafirmando o olhar "estereotipado" existente como reforço dos valores hegemônicos. Neste último caso, servindo como mais um produto fabricado dentro dos moldes da 
indústria cultural que objetiva, entre outros, o lucro.

Assim, de acordo com VALA \& MONTEIRO (2004, p. 495, a minoria se baseia na sua própria estrutura social e cultural para formar a sua representação, e é a partir destas estruturas socioculturais que ela desenvolve as suas redes de relações identitárias. Portanto, a representação é a maneira encontrada pelo indivíduo de se mostrar para o outro e transformar isto em uma ferramenta repleta de simbolizações e significações.

É importante destacar que essa luta emancipatória dos grupos minoritários é antes de tudo um luta simbólica que acontece entre outros espaços na arena da mídia, e que, portanto, pressupõe de resistência por parte dos grupos dominantes, que não aceitam dividir / perder o controle da situação. Conforme Debra P. AMORY (apud SHOHAT \& STAM, 2006, p.450) para as "minorias", é muito difícil o ato de falar por si mesmo, pois quem está no poder não quer dividi-lo e, quando é ameaçado a partir da luta por emancipação (autorrepresentação), esses grupos negam a existência da diversidade social - da diferença. Assim, é possível pensar a produção cultural e simbólica tanto como reprodução - a partir do momento em que as falas individuais repetem fórmulas consensuais ou refletem o ideário hegemônico - como também possibilidade teórica para o surgimento de práticas discordantes ou contestadoras, que podem transformar os significados periféricos ou inaceitáveis em legítimos e incorporá-los à formação discursiva.
Mas, mesmo considerando que a diversidade das experiências objetivas inviabilize uma aceitação completa das mensagens recebidas e que as interpretações sejam diferenciadas conforme as diferentes mediações que se interpõem entre produtores e consumidores culturais, os meios de comunicação não deixam de atuar no sentido de reforçar e reafirmar vários aspectos da cultura hegemônica.

\section{A mídia como ferramenta estratégica}

Com o desenvolvimento das novas tecnologias que facilitaram e desenvolveram o processo de comunicação, os grupos minoritários estão se mostrando ao mundo com o objetivo de quebrar o silêncio, expor a diversidade social, divulgar sua cultura, a partir de uma nova perspectiva antes calada pelos grupos dominantes. Segundo FREIRE FILHO (2005, p.2021) é através dos significados produzidos pelas representações que se dá sentido à experiência humana: o que se é e o que se quer ser, ou seja, é através destes significados que se posiciona e, portanto, se fala.

As políticas das identidades estão em constante luta pela autorrepresentação. De acordo com STAM \& SHOHAT (2006, p.445) os meios audiovisuais, e mais recentemente a internet, estão associados a uma atmosfera dominada por essas políticas das identidades e pelas questões de autorrepresentação a respeito de quem fala, quando, como e em nome de quem. 
Há muito tempo, o papel da cultura da mídia vem sendo reconhecido como de grande importância no sentido de reforçar e/ou propor valores e comportamentos socialmente aceitos. Assim, é através dos que os conhecem, como representações sociais, que eles formam suas concepções sobre o mundo e sobre eles mesmos.

Toda atividade de um individuo se passa num periodo caracterizado por sua presença contínua diante de um grupo particular de observadores e que tem sobre estes alguma influência. [...] Quando o individuo se apresenta diante dos outros, seu desempenho tenderá a incorporar e exemplificar os valores oficialmente reconhecidos pela sociedade. (GOFFMAN, 1985, p.29)

Isso ocorre porque, o conteúdo de uma representação para compor o imaginário social de determinada sociedade (fazendo parte do processo identitário), precisa, de antemão, incorporar os valores preexistentes nela como forma de facilitar a "digestão" do conteúdo. Conforme SHOHAT \& STAM, (2006, p.274), os valores ideológicos da plateia podem influenciar nas produções cinematográficas, uma vez que esta sociedade precisa estar "preparada" para o conteúdo proposto pelo filme. Assim, as plateias dominantes acabam por exercer um tipo de hegemonia indireta.

Conseguir se mostrar para o grande público através da mídia passou a ser uma tarefa quase que "obrigatória" para os grupos minoritários diante das inúme- ras possibilidades que as novas tecnologias lhe oferecem, fazendo da mídia uma grande aliada para a representação ou a autorrepresentação, como forma de expor uma realidade ainda "virgem" aos olhos do mundo (acostumados ao olhar hegemônico dos grupos de poder), e/ou uma realidade a partir de uma nova perspectiva.

Porém, nem sempre essa representação consegue transpor para a linguagem audiovisual o verdadeiro contexto sociocultural no qual está inserido o grupo representado. Isso ocorre porque a obra audiovisual, qualquer que seja ela, não é propriamente mostrada, mas sim representada. De acordo com GOMES (2004), uma obra audiovisual é antes de tudo, fonte de representação. Portanto, a representação está condicionada a diversos fatores, e o cinema, por exemplo, não é o reflexo da realidade, mas apenas a representa sobre determinados ângulos / perspectivas. BAKHTIN, (apud SHOHAT \& STAM, 2006, p.264,265), afirma que o cinema (como arte), é “... uma rede de signos endereçados por um sujeito ou sujeitos constituídos historicamente para outros sujeitos constituídos socialmente, todos imersos nas circunstâncias históricas e nas contingências sociais."

Usando as definições propostas por MARTIN, (2003, p.57), pode-se identificar os fatores que influenciam na representação em uma obra audiovisual como: elementos fílmicos específicos (planos de filmagem, montagem etc.) e elementos fílmicos não específicos (o discurso, iluminação, cenário, figurino etc.). Os 
elementos fílmicos específicos são elementos que somente a linguagem audiovisual os utiliza, e elementos fílmicos não específicos são os demais elementos que compõem a linguagem audiovisual, mas não são exclusivamente dela. Assim, a representação por estar condicionada (sofrer influência) de diferentes fatores, ela apenas aborda fragmentos da realidade como parte do conteúdo proposto, mas não pode se comprometer a fazer uma cópia idêntica do todo, uma vez que variáveis como contexto histórico, valores ideológicos, entre outros, estão em constante movimento e, portanto, não podem ser "enquadrados" dentro de uma só perspectiva.

$A$ identidade pós-moderna, então, é constituida teatralmente pela representação de papéis e pela construção de imagens. Enquanto o lugar da identidade moderna girava em torno da profissão e da função na esfera pública (ou familiar), a identidade pós-moderna gira em torno do lazer e está centrada na aparência, na imagem e no consumo. A identidade moderna era um negócio sério que implicava escolhas fundamentais capazes de definir quem somos (profissão, família, identificações politicas etc.), enquanto a identidade pós-moderna é uma função do lazer e baseia-se no jogo, no ludíbrio, para a produção de uma imagem (KELLNER, 2001, p.311).

Então, a identidade pós-moderna e a representação estão intimamente relacionadas com os meios audiovisuais. Isso por- que esta identidade é constituída no momento em que o audiovisual (a mídia) permeia todos os setores da vida dos sujeitos, nos momentos de lazer, de consumo e ainda no trabalho. Assim, para que determinados grupos sociais consigam a visibilidade que almejam, é necessário se apoiar e se aliar aos meios.

\section{O aparato cinematográfico e a construção do imaginário social}

Uma das características do cinema é criar uma aproximação da realidade (ou ainda ilusões de realidade), que por vezes, acaba por confundir o espectador quanto às noções de representação / realidade. Todo o discurso cinematográfico: falas, enquadramentos, iluminação, figurino, cenários, personagens etc., constituem uma rede de signos para a produção de significados quando interpretados no contexto sociohistorico no qual está inserido. Segundo KUHN (1991 apud GUBERNIKOFF, 2004, p.169)

O cinema é particularmente propenso a dar essa aparência de 'naturalidade', devido suas especificas qualidades significantes, em especial pelo fato de que a imagem filmica, ao fundamentar-se no potencial do registro da fotografia unido a projeção de uma imagem aparentemente móvel, apresenta toda a aparência de ser 'uma mensagem sem código', uma duplicação não midiatizada do 'mundo real'. (KUHN, 1991 apud GUBERNIKOFF, 2004, p. 169). 
Assim, pode-se destacar o papel do cinema na construção da identidade cultural do sujeito e na construção do imaginário social de determinada sociedade.

O cinema foi estudado como um aparato da representação, uma máquina de imagem desenvolvida para construir imagens ou visões da realidade social e o lugar do espectador nele. Mas, (...) como o cinema está diretamente implicado a produção e reprodução de significados, valores e ideologia, tanto na sociabilidade quanto na subjetividade, é melhor entendê-lo como uma prática significante, um trabalho de semiose: um trabalho que produz efeitos de significação e de percepção, auto-imagem e posições subjetivas para todos aqueles envolvidos, realizadores e espectadores; $e$, portanto, um processo semiótico no qual o sujeito é continuamente engajado, representado e inscrito na ideologia. (LAURENTIS, 1978 apud GUBERNIKOFF, 2004, p.171)

Através da criação da "impressão de realidade" o cinema atrai e segura a atenção, o fascínio do espectador nele, criando um mundo imaginário “... como forma de antecipação da resolução de uma história anteriormente conhecida, e como forma de uma reintegração social." (GUBERNIKOFF, 2004, p.176). O "compromisso" ou a representação da realidade ocorre tanto no cinema ficcional quanto no documental e, neste último, embora o compromisso com a realidade seja maior, ele não escapa dos artifícios manipulatórios do apara- to cinematográfico. (GUBERNIKOFF, 2004, p.179)

Segundo NICHOLLS (2005, p.26-27), os filmes documentários de representação social “(...) representam de forma tangível aspectos de um mundo que já ocupamos e compartilhamos. (...) Os documentários de representação social proporcionam novas visões de um mundo comum, para que as exploremos e compreendamos."

Ainda segundo ele (2005, p.27), o diferencial do cinema documental é que este convoca o espectador à reflexão de questões que merecem atenção como problemas sociais, atualidade, etc., acrescentando uma nova visão à história. Além do prazer da contemplação, assim como o filme de ficção, ele oferece, principalmente, a reflexão sobre um fato real que afeta o mundo.

Assim, é justamente nesse sentido que os grupos minoritários estão tendo a oportunidade de usufruir da mídia, em especial do cinema, para se representarem na sociedade a partir de uma nova perspectiva, que não a estereotipada pelos grupos dominantes. Com o intuito de quebrar os preconceitos preexistentes (criados a partir da perspectiva hegemônica), esses grupos minoritários buscam a reafirmação de suas identidades na luta contra o preconceito, contra a diversidade social para sua (re) inserção social, até então, negada pela cultura hegemônica.

No cinema documentário, os grupos minoritários, na sua posição de cineasta / narrador, assumem a voz de Deus, ou seja, têm o poder de falar por todos (ou melhor, por quem eles re- 
presentam) na tentativa da busca emancipatória. (NICHOLLS, 2005 , p.40). No caso do objeto de estudo deste artigo, esse cineasta assume a posição "Eu falo - ou nós falamos - de nós para nós" que conforme NICHOLLS (2005, p.45) é uma formulação que "desloca o cineasta da posição em que estava separado daqueles a quem representa para uma posição de unidade com estes últimos. $\mathrm{O}$ cineasta e aqueles que representam seu tema pertencem ao mesmo grupo."

Na tentativa de identificação dessa luta simbólica contra o preconceito da diversidade social e pela inserção social, este estudo se propõe a fazer uma análise cinematográfica do documentário canadense Carts of Darkness (2008), buscando os sentidos que emergem do discurso cinematográfico na tentativa de (re) configuração do imaginário social da sociedade contemporânea.

\section{4. $O$ cinema documentário como arma na luta pessoal - Uma breve contextualização}

Murray $\mathrm{Siple}^{3}$, cineasta canadense, é autor e diretor do documentário Carts of Darkness. Murray costumava filmar e praticar o snowboarding, além de ter total adoração por esportes radicais em geral. Mas, há cerca de 10 anos, sofreu um acidente de carro que o deixou numa cadeira de rodas, e desde então, além de estar incapacitado para a prática de tais esportes ele nunca mais produziu nenhum filme.

A partir de uma observação corriqueira de uma cena no estacionamento de um supermercado,
Murray decidiu fazer um documentário sobre um grupo de homens que catavam garrafas e latas nas ruas (como forma de subsistência) e combinado a isso, praticavam um "esporte" chamado racing shopping carts $^{4}$ pelas ruas (ingremes) em North Vancouver.

Nos preparativos para a filmagem, Murray percebeu uma certa identificação com esse grupo de "catadores de garrafas", a partir da perspectiva de que ambos fazem parte de grupos "invisíveis" (marginalizados) na sociedade, e encontrou na produção desse documentário uma forma de reviver a vida (suas identidades) de cineasta e snowboarder e, a partir disso, buscar suas identidades perdidas (em decorrência do acidente), na tentativa de reabilitação e reinserção social.

É interessante perceber nesse documentário a questão das múltiplas identidades do indivíduo pós-moderno, no qual um mesmo indivíduo compõe sua identidade a partir de grupos aparentemente contraditórios ou até sem ligação nenhuma um com o outro. Ele integra as comunidades "guardaroupa" conforme sua "conveniência": no passado de Murray ele integrava a comunidade dos snowboarders, dos cineastas e a comunidade dos capacitados a mover com facilidade; enquanto que no seu presente (durante a gravação do documentário com os shopping carts racers), ele integra a comunidade dos excluídos e aventureiros.

Murray identifica-se com o grupo a partir de 3 perspectivas distintas: indivíduos marginalizados / invisíveis na sociedade; indivíduos em busca de emoção através de esportes radicais (li-
3 As informação a seguir foram retiradas dos vídeos de making of do filme e de uma entrevista de Murray Siple à Rabble.ca, disponíveis nos sites: <http://www.nfb.ca/film/ interview-murray-siple-2/ e <http://www.nfb.ca/film/ carts-darkness-interview/>, respectivamente. Acesso em 02/05/09.

4 Esse "esporte" resume-se a descer a ladeira (ruas íngremes) em alta velocidade, apoiado sobre um carrinho de compras. 
berdade) e indivíduos portadores de necessidade especiais (caso de Furgie que apresenta lesão nos dedos das mãos que impossibilitava os movimentos). É importante destacar também que, além de escritor e diretor, Murray é também personagem (narrador e ator) do seu próprio documentário tornando ainda mais real a sua representação - representação de sua vida, dilemas, crises de identidade, etc.

Em todo o discurso cinematográfico percebe-se uma série de indícios da "desfragmentação" do sujeito pós-moderno (sendo representando pelo próprio Murray) a partir da perda de sua identidade: ex-snowboarders e ex-cineasta. A partir de uma perspectiva onde Murray se representa nos "catadores de garrafas", fica claro no filme que, após o acidente, Murray sente dificuldade de se inserir novamente na sociedade uma vez que há indícios ${ }^{5}$ de que ele mesmo e, a própria sociedade, o considera incapacitado "para a vida". Com as dificuldades físicas pelas quais passa, sente-se marginalizado pela sociedade (incapacitado fisicamente), com o agravante de que todas as atividades que participava anteriormente exigiam dele uma facilidade de locomoção.

Esse sentimento de Murray é um sentimento construído cultural e historicamente pela sociedade pós-moderna que exclui aqueles não dotados de múltiplas habilidades (não versáteis).

\section{Uma luz no fim do túnel}

O filme se inicia com Murray 5 A partir dos vídeos citados na nota 5 . boarding, sua vida era de "pura adrenalina" e ele achava que iria durar para sempre, até o seu acidente de carro que o deixou sem filmar por 10 anos. Enquanto, a narração acontece, há um jogo de cenas com pouca iluminação, que se intercalam entre closes (primeiríssimo plano) de uma pista de asfalto com câmera em movimento panorâmico (em alta velocidade), e no rosto de Murray. Num primeiro momento, a câmera dá um close no seu olho esquerdo e num segundo momento, enquadra seu rosto (close - com pouca iluminação) de perfil. A narração é interrompida por um som, mais alto que o tom de voz do cineasta / narrador, simbolizando uma batida de carro - vidro estilhaçado. Todo esse jogo de câmeras, luzes e som complementam a imaginação do espectador, inserindo-o na cena do filme. Os closes possibilitam uma maior intimidade entre espectador e personagem fazendo com que ambos vivenciem (novamente e pela primeira vez) o momento narrado, assim como os closes no rosto de Murray representam que ele está relembrando o ocorrido, ativando sua memória para a área da consciência. E o som (batida - vidro quebrando), quebra a monotonia da narrativa, simbolizando um marco na vida de Murray.

A narração da história continua, indicando que após o acidente, Murray via as montanhas como uma série de obstáculos à sua frente. A câmera mostra cenas com pouca iluminação - pôr do sol, em plano geral, de uma paisagem de região montanhosa e em seguida, mostra o céu coberto de nuvens, com câme- 
ra em contra-plongeé. As imagens representam os obstáculos e o momento obscuro pelo qual o narrador passava (paralisado numa cadeira de rodas) e o plano geral representa a solidão, a impotência que ele sentia num lugar cheio de obstáculos (dificuldade de movimentos), a paisagem o absorve e o esmaga (efeito obtido com o posicionamento de câmera em contra-plongeé).

Ao fim dessa narrativa com tom mais melancólico - relembrando momentos de tristeza, ele prossegue contando que "apareceram" uns vizinhos seus, (moradores de rua que parecia que ninguém os enxergava), que o levou para um mundo novo. Nessa parte, a paisagem que antes era de céu fechado, cheio de nuvens, começa a mudar para um céu aberto bem azul, simbolizando a liberdade, a esperança, a vida.

A cena logo muda para um close do asfalto, câmera em movimento panorâmico (em alta velocidade), filmando parte da sombra de um objeto em movimento (som de carrinho de compras), e daí ouve-se o grito de um homem vibrando - grito de euforia, liberdade.

No decorrer do documentário, ao filmar os shopping carts racers descendo as ruas de North Vancouver em altíssima velocidade, Murray busca retratar a ideia de velocidade, adrenalina, emoção, liberdade e euforia (perdida no seu passado). As câmeras se intercalam entre o movimento panorâmico (acompanhando os personagens), câmera parada para capturar imagens em movimento, e movimento de trajetória (acompa- nha o personagem e em seguida capta a paisagem ao redor).

Quando os shopping carts racers são filmados dando seus depoimentos sobre suas vidas, práticas, angústias etc., o são normalmente em plano americano. Algumas vezes seus rostos são focalizados pela câmera em primeiro plano, como se o espectador quisesse descobrir o que o personagem conta - compartilhar a intimidade da vida do personagem.

\section{A dificuldade de se desvincular do passado e de viver uma nova realidade}

O filme retrata o constante jogo entre presente e passado, dois espaços temporais conexos que jamais se cruzaram, na tentativa de superação de uma realidade ainda não assimilada pelo autor / diretor / protagonista.

Numa sequência, a câmera capta em primeiro plano garrafas se quebrando no ar (câmera lenta), e por fim a câmera para no chão focalizando (primeiro plano) os cacos das garrafas. Essa cena simboliza os riscos desse "esporte" e ao mesmo tempo remete ao acidente que "mudou" a vida de Murray, a perda de identidade e como ela se encontra nesse momento: em fragmentos desconexos.

Numa outra situação, Murray de dentro do carro passa um cigarro ao velho Furgie (ambos com deficiência nas mãos) que está de fora do carro do lado do passageiro. Nesta cena, a câmera mostra em primeiro plano toda a dificuldade física de Murray para segurar o maço e 
6 Preferiu-se manter alguns dos trechos do filme (transcrições de falas) em sua versão original (inglês), buscando manter o sentido real da fala que pode se perder quando de sua tradução para o português. tirar um cigarro para dar ao amigo e em seguida a câmera dá um close nas mãos dos dois ao se encontrarem (com dificuldades) para passar / pegar o cigarro. Essa cena representa a dificuldade e a superação dos obstáculos em nome do "companheirismo".

Em outra sequência, uma paisagem de um mar ao fundo, Murray e o velho Furgie conversam sobre suas dificuldades ao longo da vida. Durante a conversa, o velho Furgie é retratado tocando violão, com closes de câmera em suas mãos deficientes sobre o instrumento. Este foco da câmera é justamente o olhar do diretor, que é ao mesmo tempo personagem da cena sobre o problema físico do amigo, com o qual se identifica, e, portanto, busca através desta tomada a sua superação a partir da superação do amigo. Entre os closes que faz nas mãos deficientes do velho Furgie sobre o violão, a câmera também registra as de Murray: ora apoiadas nas pernas, ora pegando uma garrafa de cerveja, ora coçando o queixo, todos os movimentos apresentados com dificuldade, representando as dificuldades pelas quais passa no dia a dia.

O velho Furgie continua a conversa dizendo que já perdeu muita gente por causa do seu vício (bebida) e Murray questiona se ele se arrepende por alguma coisa que fez na vida. Furgie responde: "... No, shit happens to everybody... and you know more than everybody... it's not easy being me, it's not easy being you." ${ }^{, 6} \mathrm{O}$ que representa claramente sua posição de marginalizado na sociedade.

\section{A tentativa de quebra do preconceito contra a diversidade social}

Num determinado momento do filme, Murray conta sua história de que por muitos anos morou em North Vancouver, e embora sinta que é uma região rica e confortável, ele não se sente "em casa" ali, como se sente no meio deste novo grupo. Com isso, Murray representa sua identificação com esses moradores de rua, uma vez que com as consequências do acidente (que o colocou numa cadeira de rodas), sente-se marginalizado na sociedade. Em seguida, são apresentadas cenas de uma sequência de depoimentos de moradores da região (enquadrados em plano americano ou em closes em seus rostos), de classe média, que são beneficiados com esses catadores de garrafas (que lhes poupam trabalho) e, portanto, reconhecem sua importância na sociedade. Murray se representa e se sente representado por esse grupo de pessoas marginalizadas na sociedade e usa desta experiência para provar a si mesmo e ao espectador que, embora marginalizados, são pessoas que fazem a diferença na sociedade e que merecem ser reconhecidas e respeitadas.

\section{A identificação no outro}

Ao mesmo tempo que Murray se autorrepresenta no filme, ele também se utiliza dos outros personagens para se representar tornando a narrativa ainda mais rica simbolicamente.

Big Al um outro personagem do documentário é retratado numa cena praticando o "esporte" e nes- 
sa cena ouve-se a voz do narrador (Murray), dizendo que sabe que aquele "esporte" não é o mesmo que o snowboarding, mas que há tempos não sentia uma sensação tão boa, somente observando seu amigo. Murray se indaga quanto à sua tentativa de recuperar sua identidade (busca da identidade) na pele de outro, como diz no seguinte trecho se sua narração: "Can I capture the essence of my old life by following out depper into his?"

$\mathrm{O}$ documentário encerra com a narração de Murray ao fundo e algumas imagens que resumem sua vida: câmera em contra-plongeé filmando o céu aberto com nuvens em movimento e depois um carrinho de compras (representando a contradição entre a esperança / liberdade e a opressão do mundo / da realidade para o narrador). Por fim, uma imagem em primeiro plano em contra-plongeé de uma cadeira de rodas. A posição da câmera representa o sentimento de inferioridade do narrador diante do mundo, sentindo-se esmagado. As últimas palavras simbolizam o quanto esse documentário serviu para a busca de sua identidade e sua "nova inserção" na sociedade: "I understand exactly what it's like being offered an unwanted help. I tried helping Furgie before and I knew he wouldn't accept much more from me than a pack of smokes. Watching Furgie falls asleep have amazed me how deep these guys have allowed me into their world."

\section{Conclusão}

Os signos de luta, conflito, insegurança, exclusão, inserção são representadas ao longo do documentário como forma de denún- cia do poder hegemônico, como forma de busca da autossuperação. O cinema documental foi utilizado nesse contexto como ferramenta estratégica na luta contra a cultura hegemônica, uma prova para ele (Murray) e para a própria sociedade de que ainda está vivo e dotado de muitas habilidades, embora, agora, diferentes das anteriores. Uma prova de que os diferentes ao invés de "fragmentar", (heterogeneizar), a sociedade (visto como um ponto negativo para os grupos dominantes, pois dificulta o controle social), enriquecem-na uma vez que oferecem novas perspectivas da realidade e novas formas de viver a vida. A diversidade social abre portas para caminhos até então desconhecidos.

Murray (diretor / personagem) consegue representar-se em si mesmo e nos outros (e essa é uma questão diferencial deste documentário) de forma tão natural que fica claro ao espectador que seu documentário é uma tentativa de exposição da sua luta pessoal contra as barreiras que ele mesmo e o mundo impõem para essa nova vida, na tentativa de superação pessoal e conscientização do espectador. É uma denuncia à exclusão das diferenças nas sociedades pós-modernas, mostrando a possibilidade de inserção social destes "diferentes" sem "dores" para a sociedade. E o interessante é que ele faz isso, como se estivesse falando do outro que num primeiro momento nada tinha a ver com sua história de vida.

Porém, cabe destacar que Murray só conseguiu perceber isso quando foi, por uma ironia do destino, colocado na condição de minoria, o que mostra que este filme busca não somente romper com o 
preconceito dos outros, mas dele lhou mais ativamente dos valores mesmo, que um dia já comparti- hegemônicos.

\section{Referências Bibliográficas}

BAUMAN, Zygmunt. Identidade. Rio de Janeiro: Jorge Zahar Editor, 2005. . Modernidade líquida. Rio de Janeiro: Jorge Zahar Ed., 2001. Zahar Ed., 1998. O mal-estar da pós-modernidade. Rio de Janeiro: Jorge

HALL, Stuart. A identidade cultural na pós-modernidade. Rio de Janeiro: DP\&A, 2006.

FREIRE FILHO, João. Força de expressão: construção, consumo e contestação das representações midiáticas das minorias. Revista FAMECOS, Porto Alegre, n.28, p. 18-29, dezembro, 2005.

GOFFMAN, Erving. A representação do eu na vida cotidiana. Petrópolis, Vozes, 1985.

GOMES, Wilson. Apontamentos sobre o conceito de esfera pública política. In: MAIAIR.

GUBERNIKOFF, Giselle. O Aparato Cinematográfico. Comunicação: Veredas, Ano III, No 03, Novembro, 2004, p.167-180.

KELLNER, Douglas. A Cultura da mídia. São Paulo: EDUSC, 2001.

MARTIN, Marcel. A linguagem cinematográfica. São Paulo: Brasiliense, 2003.

NICHOLLS, Bill. Introdução ao documentário. Campinas-SP: Papirus Editora, 2005. p.26-70.

SHOHAT, Ella \& STAM, Robert. Crítica da imagem eurocêntrica: multiculturalismo e representação. São Paulo: COSACNAIFY, 2006.

VALA, Jorge; MONTEIRO, Maria Benedicta. Psicologia Social. Lisboa: Fundação Calouste Gulbenkian, 2004.

Fontes eletrônicas:

$<$ http://www.nfb.ca/film/carts_of_darkness/>.Acesso em 02/05/2009. $<$ http://www.nfb.ca/film/interview-murray-siple-2/>.Acesso em 02/05/2009. $<$ http://www.nfb.ca/film/carts-darkness-interview/>. Acesso em 02/05/2009. 
